\title{
Combined Endoscopic Transanal Vacuum-Assisted Rectal Drainage: A Novel Therapy for Colorectal Anastomotic Leak after TME for Cancer
}

\author{
Mario Martinotti ${ }^{*}$, Valerio Ranieri ${ }^{1}$, Elena Iiritano ${ }^{2}$, Teresa Staiano ${ }^{2}$, Roberto Dusi ${ }^{3}$, \\ Ernesto Laterza ${ }^{3}$, Federico Buffoli ${ }^{2}$ \\ ${ }^{1}$ Departement of General Surgery, IstitutiOspitalieri di Cremona, Cremona, Italy \\ ${ }^{2}$ Endoscopy Unit, IstitutiOspitalieri di Cremona, Cremona, Italy \\ ${ }^{3}$ General Surgery Unit, Ospedale Oglio Po, Casalmaggiore, Italy \\ Email: ${ }^{*}$ m.martinotti@ospedale.cremona.it
}

Received 19 August 2014; revised 16 September 2014; accepted 10 October 2014

Copyright (C) 2014 by authors and Scientific Research Publishing Inc.

This work is licensed under the Creative Commons Attribution International License (CC BY). http://creativecommons.org/licenses/by/4.0/

c) (i) Open Access

\begin{abstract}
Introduction: Low colorectal and colo-anal anastomosis leakage after anterior resection of rectum occurs in up to $24 \%$ of cases. Leak is the main cause of morbidity and mortality in postoperative period and can result in a permanent stoma in up to $25 \%$ of cases. Loop ileostomy or colostomy does not reduce the percentage of fistulas, but reduces flow rate. Conservative management imply long times to heal. Endosponge ${ }^{\circledR}$ system (B. Braun Aesculap AG, Germany) was recently acquired in clinical practice. This system accelerates healing process through vacuum creation, removal of fluids and edema, infection control, local increase of blood flow and stimulation of granulation tissue formation. The device consists of a cylindrical polyurethane sponge, with 400 to 600 micron pores, standard dimension of $7 \mathrm{~cm}$, which can be cut to fit the estimated size of the abscess cavity. The drain tube is connected to a Redyrob Trans Plus $®$ bottle which exerts a constant suction during the therapy. Materials and Methods: From November 2012 and March 2014 four patients were treated with Endosponge ${ }^{\circledR}$ system, all of them underwent operation of anterior resection of rectum for cancer and developed anastomotic leakage during postoperative course. All patients had loop ileostomy, none presented signs of sepsis. The Endosponge ${ }^{\circledR}$ system was then placed endoscopically. In all cases, after the first placing, the authors utilized sterile foam dressing from negative pressure wound therapy kit, tailored to better fill the abscess cavity and connected with Redyrob Trans Plus $®$ bottle. Device changes were performed every 5 - 7 days, according to the size of the cavity and the amount of secretions produced. The treatment was started during hospitaliza-
\end{abstract}

\footnotetext{
${ }^{*}$ Corresponding author.
} 
tion first and then continued as outpatient. Results: There was no mortality. The amount of secretions was related to the initial size and the degree of contamination of the abscess cavity. Antibiotic therapy was discontinued after an average of 21 days, with a range between 14 and 32 days. Complete healing was achieved in a median of 82 days (30 to 148) in all patients with good functional results, no further surgery was required. Conclusions: The results of therapy with Endosponge ${ }^{\circledR}$ seem encouraging. Success of therapy is higher if initiated as soon possible after the intervention and is also related to the size of dehiscence and abscess cavity. In cases with large abscesses, it is not clear whether this new treatment leads to reduction in healing time, however, can prevent the packaging of a (often definitive) colostomy. Further studies will be able to select patients who will most benefit from the procedure.

\section{Keywords}

\section{Endosponge ${ }^{\circledR}$, Colorectal Anastomotic Leak, Transanal Vacuum Therapy}

\section{Case 1}

An 86-year-old woman with T2 N0 rectal cancer, treated with neoadjuvant radio-chemotherapy and subsequently underwent laparoscopic TME with a loop-ileostomy. In the ninth post-operative day fecal collection from the abdominal drain was noticed. Abdominal CT proved multiple pelvic fluid collections in the fatty tissue. Rectoscopy showed a dehiscence of $8 \mathrm{~mm}$, which communicates with the cavity thoroughly cleaned, washed and treated with gentamicin and placement of OTSC with closure of dehiscence. After 2 weeks, endoscopic control highlights OTSC free in the stump and presence of dehiscence $12 \mathrm{~mm}$ in diameter, which gave access to a large cavity; washing was practiced and positioned Spongostan ${ }^{\circledR}$. Control after 7 days under the same: it takes then treatment with Endosponge ${ }^{\circledR}$ with 5 dressing changes in 36 days. Persistence of small cavity in the bottom $15 \mathrm{~mm}$ the patient was treated with an incision of remaining septum with precut needle. After 30 days presence of an ulcerated area, outcome of the section of the septum, was seen in the absence of fistulas. There was no co-morbidity during treatment. Total treatment time: 64 days.

Loop ileostomy was subsequently closed and the patient reported good fecal continence.

\section{Case 2}

A 66-year-old man with T3 N1 rectal cancer, treated with neoadjuvant radio-chemotherapy, subsequently underwent laparoscopic TME with a loop-ileostomy. He developed after 6 months, in course of adjuvant radiotherapy, massive rectal bleeding and anal pain radiating left coxofemoral joint. An MR of the pelvis showed presence of an anastomotic leak with abscess cavity involving the muscles of the pelvic floor and left ischiorectal fossa. The rectoscopy confirmed anastomotic leak that gave access to a large abscess cavity containing pus and necrotic debris. After an initial attempt at endoscopic drainage of necrosis, treatment was undertaken with Endosponge ${ }^{\circledR}$. Nine dressing changes were made weekly for a total of 48 days. The patient was then treated in 3 sessions with endoscopic application of fibrin glue in the residual cavity, for a total of another 10 days. Endoscopic control at 30 days showed complete re-epithelization of the dehiscence. There was no co-morbidity during treatment.

Total treatment time: 48 days.

The loop ileostomy was subsequently closed and the patient reported good fecal continence.

\section{Case 3}

A 65-year-old female with T2 N0 rectal cancer underwent laparotomic TME anterior resection of the rectum with colo-anal anastomosis and contemporary loop-ileostomy. Distance to a week after surgery, for the appearance of fecal drainage from the tube in the pelvis was diagnosed wide dehiscence of the anastomosis which involves half of the colonic lumen, with two distinct abscess cavity 15 and $12 \mathrm{~cm}$ depth. After an unsuccessful attempt transanal manual suture, the treatment with Endosponge ${ }^{\circledR}$ was started. Nine dressing changes were made 
using 14 sponges ( 2 sponges for the first 5 sessions and a unique sponge in the next 4 sessions) weekly for a total of 55 days. The residual cavity was treated with positioning Vycril ${ }^{\circledR}$ mesh with re-epithelization of the cavity. After 14 days was placed Promogran ${ }^{\circledR}$ in the only remaining cavity and, after two weeks, three applications of fibrin glue on a biweekly basis. There was no co-morbidity during treatment.

Total treatment time: 148 days.

The patient is currently asymptomatic and awaiting intervention closure of ileostomy.

\section{Case 4}

A 70-year-old female with T3 N1 rectal cancer, treated with neoadjuvant radio-chemotherapy, subsequently underwent laparoscopic TME with a loop-ileostomy and left salpingectomy for suspected infiltration. In seventh postoperative day showed the presence of purulent material from the pelvis drain. The CT showed the presence of left para-uterine collection. Rectoscopy observed anastomotic dehiscence at $12 \mathrm{~mm}$ in diameter with access to abscess cavity deep about $20 \mathrm{~cm}$. Treatment with Endosponge ${ }^{\circledR}$ was immediately undertaken with six dressing changes weekly for a total of 41 days. The small residual cavity was treated by the insertion of Vycril ${ }^{\circledR}$ mesh. After 7 days was observed, at removal of Vicryl ${ }^{\circledR}$ mesh, presence of a rectovaginal fistula with migration of part of the mesh in the vaginal cavity. The orifice had a diameter of $2 \mathrm{~mm}$. Three sessions were carried out with endoscopic placement of fibrin glue, with evidence of closure of rectovaginal fistula and anastomotic leak.

No other co-morbidity during treatment were observed.

Total treatment time: 86 days.

The patient is currently asymptomatic and awaiting intervention closure of ileostomy.

\section{Discussion}

Dehiscence of the anastomosis colo-rectal or colo-anal low is a complication that can have serious consequences for the patient. Presence of ileum or colostomy does not reduce the percentage of fistulas [1], but reduces the flow rate [2]. Many surgeons repackage a protective stoma in anterior resection of the rectum into the habit. In cases of dehiscence you can wait and see after diversion of the fecal transit or establish a more aggressive treatment to prevent further complications and achieve a safer resolution process [3]. The negative pressure therapy has been proposed as minimally invasive method for the healing of the fistula from the first literature description by Nagell and Holte in 2006 [4]. To this end, you can use the commercial device or draw a similar craft [5]. The data in the literature indicate a high success rate in closing fistulas achieved in less time than patients not treated with vacuum [6]-[9]. The authors seem to agree with advantageous initiation of therapy before six weeks after surgery, as starting later is burdened with longer healing and a high number of failures [3]. In addition to the healing of the leak and the time in which it is obtained is important to evaluate the functional results [7]. In our limited experience we integrated the use of vacuum therapy with the use of endoscopic techniques such as positioning of Vicryl ${ }^{\circledR}$ mesh ( 2 cases), the use of advanced dressings as the Promogran ${ }^{\circledR}(1$ case), the use of glue fibrin ( 4 cases) and the positioning of endoscopic clip (1 case). All the patients treated obtained a healing of the fistula without the need for further surgery, functional recovery after protection ileostomy closure was satisfactory. Resolution time depended on the establishment of the earliness of vacuum therapy and the size of the sinus to treat. The mean time to healing was 82 days, with a range between 30 and 148 days. The degrees of patient satisfaction and pain, especially related to dressing changes, were more than acceptable. Is controversial whether to perform the treatment on an inpatient or outpatient basis, whether to perform dressing changes under general anesthesia or mild sedation, which time interval interposed between a medication and the other [10]. We started the treatment on an inpatient basis in all cases and subsequently continued on an outpatient basis, always in the room with endoscopic and mild sedation. Whether to carry out the procedure every 3 or 7 days, depended on the size of the cavity pararectal by the amount of secretions produced and the negative pressure applied. Greater is the vacuum applied to the sponge, more and more tenacious adhesions and difficult will be to removal of the sponge in the case where the interval between a dressing and the other exceeds three days. Some authors have reported the recurrence of fistula post recanalization. In our experience this has never happened, however, should assess the impact of chemotherapy and radiotherapy after the recanalization. Remains to evaluate the impact of conservative therapy has on time delay of adjuvant therapy starting compared with a demolitive approach which implies packing a colostomy which often becomes permanent. A final comment concerns the costs of the proceedings, which are not insignificant; they depend not only on the price of the device but also from 
inpatient or outpatient anesthesia used and the place where it occurs dressing changes (surgery or endoscopic room [11]). In conclusion, the results of vacuum therapy integrated with other endoscopic techniques and the use of modern materials medicated seem encouraging in the treatment of colorectal and colo-anal anastomotic leakage rates. The success of therapy is higher when established as soon as possible before surgery; depends, then, on the size of the pararectal cavity and caliber of the dehiscence. Further studies will be able to select patients who can most benefit from conservative procedures.

\section{References}

[1] Gastinger, I., Marusch, F., Steinert, R., Wolff, S., Koeckerling, F. and Lippert, H. (2005) Protective Defunctioning Stoma in Low Anterior Resection for Rectal Carcinoma. British Journal of Surgery, 92, 1137-1142. http://dx.doi.org/10.1002/bjs.5045

[2] Tan, W.S., Tang, C.L., Shi, L. and Eu, K.W. (2009) Meta-Analysis of Defunctioning Stomas in Low Anterior Resection for Rectal Cancer. British Journal of Surgery, 96, 462-472. http://dx.doi.org/10.1002/bjs.6594

[3] van Koperen, P.J., van Berge Henegouwen, M.I., Rosman, C., Bakker, C.M., Heres, P., Slors, J.F. and Bemelman, W.A. (2009) The Dutch Multicenter Experience of the Endo-Sponge Treatment for Anastomotic Leakage after Colorectal Surgery. Surgical Endoscopy, 23, 1379-1383. http://dx.doi.org/10.1007/s00464-008-0186-4

[4] Nagell, C.F. and Holte, K. (2006) Treatment of Anastomotic Leakage after Rectal Resection with Transrectal VacuumAssisted Drainage (VAC). A Method for Rapid Control of Pelvic Sepsis and Healing. International Journal of Colorectal Disease, 21, 657-660. http://dx.doi.org/10.1007/s00384-005-0083-4

[5] Verlaan, T., Bartels, S.A., van Berge Henegouwen, M.I., Tanis, P.J., Fockens, P. and Bemelman, W.A. (2011) Early, Minimally Invasive Closure of Anastomotic Leaks: A New Concept. Colorectal Disease, 13, 18-22. http://dx.doi.org/10.1111/j.1463-1318.2011.02775.x

[6] Waidenhagen, R., Hartl, W.H., Gruetzner, K.U., Eichhorn, M.E., Spelsberg, F. and Jauch, K.W. (2010) Anastomotic Leakage after Esophageal Resection: New Treatment Options by Endoluminal Vacuum Therapy. The Annals of Thoracic Surgery, 90, 1674-1681. http://dx.doi.org/10.1016/j.athoracsur.2010.07.007

[7] von Bernstorff, W., Glitsch, A., Schreiber, A., Partecke, L.I. and Heidecke, C.D. (2009) ETVARD (Endoscopic Transanal Vacuum-Assisted Rectal Drainage) Leads to Complete but Delayed Closure of Extraperitoneal Rectal Anastomotic Leakage Cavities Following Neoadjuvant Radiochemotherapy. International Journal of Colorectal Disease, 24, 819-825. http://dx.doi.org/10.1007/s00384-009-0673-7

[8] Riss, S., Stift, A., Meier, M., Haiden, E., Grümberger, T. and Bergmann, M. (2010) Endo-Sponge Assisted Treatment of Anastomotic Leakage Following Colorectal Surgery. Colorectal Disease, 12, e104-e108.

[9] Mees, S.T., Palmes, D., Menningen, R., Senninger, N., Haier, J. and Bruewer, M. (2008) Endo-Vacuum Assisted Closure Treatment for Rectal Anastomotic Insufficiency. Diseases of the Colon and Rectum, 51, 404-410.

[10] Arezzo, A., Miegge, A., Garbarini, A. and Morino, M. (2010) Endoluminal Vacuum Therapy for Anastomotic Leaks after Rectal Surgery. Techniques in Coloproctology, 14, 279-281. http://dx.doi.org/10.1007/s10151-010-0569-0

[11] Srinivasamurthy, D., Wood, C., Slater, R. and Garner, J. (2013) An Initial Experience Using Transanal Vacuum Therapy in Pelvic Anastomotic Leakage. Techniques in Coloproctology, 17, 275-281. http://dx.doi.org/10.1007/s10151-012-0911-9 
Scientific Research Publishing (SCIRP) is one of the largest Open Access journal publishers. It is currently publishing more than 200 open access, online, peer-reviewed journals covering a wide range of academic disciplines. SCIRP serves the worldwide academic communities and contributes to the progress and application of science with its publication.

Other selected journals from SCIRP are listed as below. Submit your manuscript to us via either submit@scirp.org or Online Submission Portal.
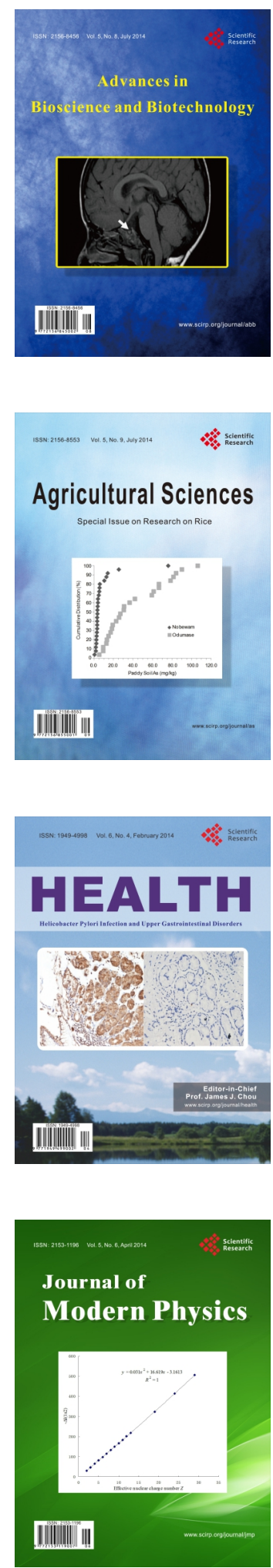
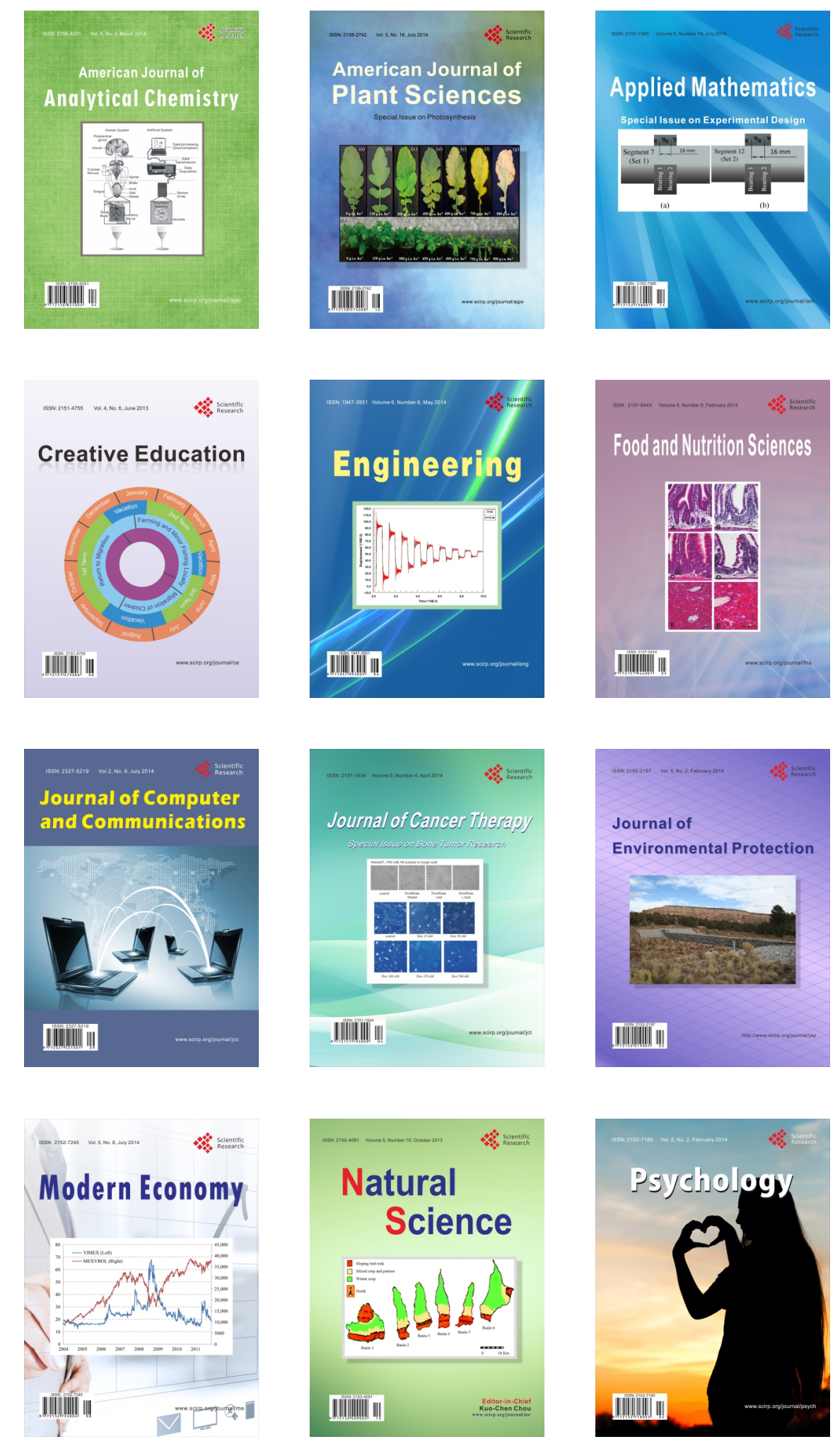